2011;131(6):797-802

4. Liu Sh, Liu km, Wang aq, Gui zg, Han xz, Wang f. Management strategies for posttraumatic knee stiffness. Biomedical. 2016.

5. Parisien JS. The role of arthroscopy in the treatment of postoperative fibroarthrosis of the knee joint. Clin Orthop. 1988;(229):185-192.

6. Pujol $N$, Boisrenoult $P$, Beaufils $P$. Posttraumatic knee stiffness: Surgical techniques.
Orthop Traumatol Surg Res. 2015;101(1 Supplement):S179-S186.

7. Vaish A, Vaishya R, Bhasin VB. Etiopathology and Management of Stiff Knees: A Current Concept Review. Indian J Orthop. 2021;55(2):276-284.

8. Alm L, Klepsch L, Akoto R, Frosch K-H. Arthrofibrosis of the knee: clinical result after early vs. late arthroscopic arthrolysis of 100 patients. Orthop J Sports Med. 2020;8

\title{
KÊTT QUẢ HÓA XA TRỊ ĐỒNG THỜI PHÁC ĐỒ EP VÀ KĨ THUẬT XẠ ĐIỀU BIẾN LIỀU TRONG UNG THƯ PHỔI KHÔNG TẾ BÀO NHỎ GIȦI ĐOẠN III
}

\section{TÓM TẮT}

Mục tiêu: Đánh giá kết quả điều trị của phác đồ EP kết hớp với xa trị điều biến liều trong ung thư phổi không tế bào nhỏ giai đoạn III và mô tả một số tác dụng không mong muốn của điều trị trên. Đổi tượng nghiên cứu: Gồm 37 bệnh nhân UTPKTBN giai đoạn III được điêu tri hoá xa tri đồng thời bằng kĩ thuât xa điêu biến liêu và phác đồ hoá chất etoposide-cisplatin tại Bệnh viện K từ 01/2019 đến 06/2021. Phương pháp nghiển cứu: mô tả cắt ngang. Kết quả: Đặc điểm nhóm nghiên cứu: Tuổi trung bình 57 , tỉ lệ nam chiến $86,5 \%$, bệnh nhân được lựa chọn có thể trạng tốt với $22(59.5 \%)$ trong 37 bệnh nhẩn ECOG 0. Giai đoạn bệnh chủ yếu là giai đoạn IIIB chiếm $62,2 \%$, mô bệnh học chủ yếu là carcinoma tuyến $64.9 \%$. Kết quả điều tri: Đánh giá đáp ứng theo RECIST 1.1 cho thây tî lệ đáp ứng toàn bộ, một phần tương ứng là $2,7 \%$ và $83,8 \%$, tỉ lệ kiểm soát bệnh là $97,3 \%$. Thời gian trung vị sống thêm không tiến triển là $14 \pm 3,7$ tháng. Sống thêm không tiến triển vào thời điểm 12 tháng là $54,7 \%$ là Độc tính: Có 24,3\% bệnh nhân viêm phổi, $44,2 \%$ bệnh nhân viêm thực quản chỉ ở độ I, II. Độc tính trên hệ tạo huyết chủ yếu độ I, II, chỉ có $2,7 \%$ bênh nhân xuất hiện độ III. Độc tính trên gan, thân, nổn, mệt mỏi, sụt cân đều ở mức độ 1-2. Kết luận: Phác đồ không những cho kết quả khả quan về đáp ứng và sống thêm không tiến triển, mà còn giảmđáng kể các độc tính liên quan đến xa trị

Tư khóa: Ung thư phổi khổng tế bào nhỏ, hóa xạ trị đồng thời, EP, tỉ lệ đáp ứng, độc tính.

\section{SUMMARY \\ RESULTS OF CONCURRENT CHEMORADIOTHERAPY WITH ETOPOSIDE - CISPLATIN REGIMEN AND INTENSITY}

\footnotetext{
${ }^{1}$ Trường Đại học Y Hà Nội

²Bệnh viện $K$ trung ương

Chịu trách nhiệm chính: Nguyễn Quang Anh

Email: quanganhyd@gmail.com

Ngày nhận bài: 3.8.2021

Ngày phản biên khoa họ: 1.10 .2021

Ngày duyệt bài: 8.10.2021
}

\section{Nguyễn Quang Anh' ${ }^{1}$, Đỗ Hùng Kiên², Nguyễn Văn Tài ${ }^{2}$, Lê Thị Yến ${ }^{2}$}

MODULATE RADIATION IN STAGE III NON - SMALL CELL LUNG CANCER

Objectives: To evaluate the treatment results of EP regimen combined with dose-modulated radiotherapy in stage III non-small cell lung cancer and describe some undesirable effects of the treatment regimen. Patients and methods: 37 patients with stage III NSCLC who received chemotherapy and radiotherapy concurrently with intensity modulated radiation therapy and etoposidecisplatin chemotherapy regimen at K Hospital from January 2019 to June 2021. Results: Study group characteristics: Mean age 57, men account for $86,5 \%$, selected patients were in good performance status with $22(59,5 \%)$ in 37 ECOG 0 patients. Stage host disease mainly stage IIIB accounts for $62.2 \%$, histopathology is mainly adenocarcinoma $64.9 \%$. Treatment results: Evaluation of response according to RECIST 1.1 showed that the rate of complete and partial response was $2,7 \%$ and $83,8 \%$, respectively. Progression-free survival was $14 \pm 3,7$ months. Progression-free survival at 12 months $54,7 \%$ was Toxicity: There were $24,3 \%$ pneumonia patients, $44,2 \%$ esophagitis patients only grade I, II. Toxicity on hematopoietic system mainly grade I, II., only $2.7 \%$ of patients appeared grade III. Toxicity on liver, kidney, vomiting, fatigue, weight loss are at 1-2 levels. Conclusion: The regimen not only gave good results in terms of response rates and progression-free survival, but also significantly reduced radiationrelated toxicity

Keywords: Lung cancer, concurrent chemoradiotherapy, EP, response rate, toxicity..

\section{I. Đă̆T VẤN ĐỀ}

Hóa xạ trị đồng thời là phương pháp điều trị chuẩn ở bệnh nhân ung thư phổi không tế bào nhỏ (UTPKTBN) giai đoạn III không có chỉ định phẫu thuật. Giai đoạn này gặp khoảng 30\% tại thời điểm chẩn đoán ban đâu và tỷ lệ sống thêm 5 năm dao động từ $5 \%$ đến $17 \%$, kết quả này phụ thuộc vào phương pháp điêu trịi ${ }^{1}$. Việc phối hợp hoá xạ trị có hai mục đích, một là hoá chất 
làm tăng tác dụng của xạ trị, điều này đã được minh chứng qua nhiều nghiên cứu, hai là hoá chất có tác dụng tiêu diệt các ổ vi di căn xa mà các phương tiện chẩn đoán có thể chưa phát hiện được. Có nhiều hình thức phối hợp như hoá xạ tuần tự, hoá xạ đồng thời, hoá xạ xen kẽ, tuy nhiên theo nghiên cứu của Curran và cộng sự (2003), Auperin (2010) thì hoá xạ đồng thời cho tỷ lệ đáp ứng cao nhất, dao động trong khoảng $84 \%$ so với $66 \%$ của hóa xạ tuân tự ${ }^{2}$. Đối với UTPKTBN, phác đồ hoá chất trong HXĐT có nền platinum nhu Etoposid-cisplatin, PemetrexedCisplatin, Paclitaxel-Carboplatin, các nghiên cứu cho thây phác đồ EP mang lại hiệu quả cao trong điều trị phối hợp xạ trị trên nhóm $B N$ giai đoạn III $^{3}$.Kî thuât xa trị điều biến liều với hiẹu quả kiểm soát tại chỗ tốt và giảm độc tính với cơ quan lân cận tối đa từ đó do đó cải thiện kết quả điều trị và dung nạp của bệnh nhân tốt hơn ${ }^{4}$. Tại bệnh viện $K$, việc điều trị UTPKTBN giai đoạn III không phẫu thuật đượcbằng hoá xạ đồng thời phác đồ EP kết hợp xạ trị điều biến liều đã được thực hiện từ năm 2018 và đem lại hiệu quả điểu trị cao cho bệnh nhân. Tại Việt Nam chưa có nghiên cứu về vấn đề này nên chúng tôi tiến hành đề tài: "Kết quả điều trị của phác đồ EP kêt hợp với xa trị điều biến liều trong ung thư phổi không tê bào nhỏ giai đoạn III".

\section{II. ĐỐI TƯỢNG VÀ PHƯƠNG PHÁP NGHIÊN CỨU}

1.Đối tượng nghiên cứu: Gồm các bệnh nhân UTPKTBN giai đoạn III được điều trị hoá xạ trị đồng thời bằng kĩ thuật xạ điều biến liều (IMRT)và phác đồ hoá chất etoposide-cisplatin tại Bệnh viện K 01/2019 đến 06/2021.

Tiêu chuẩn lựa chọn: - Chẩn đoán xác định bằng mô bệnh học là ung thư phổi không tế bào nhỏ.

- Chẩn đoán giai đoạn bệnh IIItheo AJCC 2017.

- Bệnh nhân được điều trị hóa xạ đồng thời bằng kĩ thuật IMRT (xạ trị điều biến liều) và hóa chất phác đồ Etoposide- cisplatin x 2 chu kì.

- Thể trang tốt: ECOG 0 -1

- Có tổn thương đích có thể đo và đánh giá được trên trên chẩn đoán hình ảnh theo tiêu chuẩn RECIST v1.1

- Chức năng gan, thận trong giới hạn cho phép điều trị phác đồ.

Tiêu chuẩn loại trừ:

- Có bệnh lý nội, ngoại khoa nặng hoặc mắc thêm các bệnh ung thư khác.

- Có bệnh lý kèm theo mà xạ trị lồng ngực và điều trị hóa chất nguy hại đến bệnh nhân như: nhồi máu cơ tim, suy tim, loạn nhịp tim, các bệnh lý nhiễm khuẩn chưa kiểm soát được.
- Hồ sơ lưu trữ không có đủ thông tin nghiên cứu - Bệnh nhân không hợp tác, không theo dõi được.

\section{Phương pháp nghiên cứu}

Thiết kế nghiên cứu: Nghiên cứu mô tả kết hợp hồi cứu và tiến cứu.

$$
\text { Cỡ mẫu } n=Z_{\left(1-\frac{g}{2}\right)}^{2} \frac{1-P}{\varepsilon^{2}{ }^{2} P} \text { : }
$$

Trong đó: $\mathrm{N}$ là cõ mẫu. $\mathrm{a}=0.05 . \mathrm{P}=0.73$ là tỉ lệ đáp ứng toàn bộ ở bệnh nhân UTPKTBN giai đoạn III không phẫu được điêu trị hóa xạ đồng thời bằng phác đồ etoposide - cisplatin theo nghiên cứu trước (Liang và $C^{3}{ }^{3}$ 2017). Tính đươc cơ mẫu tối thiểu là 35 bênh nhân.

Các bước tiến hành: Thu thập số liệu bệnh nhân dựa trên bệnh án nghiên cứu. Thu thập theo các biến tuổi, giới,chỉ số toàn trạng PS, giai đoan bênh, thể mô bênh hoc, kích thước u và hach trước và sau điều trị, thời gian bắt đầu điều trị, thời gian tái phát hoặc tiến, các độc tính xảy ra trong quá trình điều trị.

Phân tích số liệu: Dựa trên phần mềm SPSS 20.0.

Phác đồ điêuu trị: Phác đồ $E P$, gồm 2 chu kì truyền hóa chất cùng với tia xạ.Cisplatin 50 $\mathrm{mg} / \mathrm{m} 2 \mathrm{da}$, truyền TM ngày 1,5,29,36; Etoposide $50 \mathrm{mg} / \mathrm{m} 2 \mathrm{da}$, truyền TM ngày 1-5, 29-33. Xa trị sẽ được bắt đầu từ ngày đâuu tiên truyền hóa chất 1.8-2 Gy/ngày, tổng liều xạ từ 60-63Gy.

Đánh giá đáp ứng điều trị:

- Đánh giá đáp ứng: Theo tiêu chuẩn (RECIST 1.1), dựa trên lâm sàng và chụp chụp CLVT sau khi kết thúc điêu trị, có so sánh với CLVT trước điều tri.

Đánh giá thời gian sống thêm không tiến triển theo phương pháp Kaplan - Meier.

- Đánh giá độc tính điều trị theo CTCAE 4.0. Ghi nhân độc tính đầu mỗi chu kì hóa trị và sau mỗi 2 tuần xă.

3. Đạo đức nghiên cứu: Nghiên cứu đã được thổng qua tại hội đồng đạo đức Bệnh viện $K$ và Bệnh viện Đại học $Y$ Hà Nội.

\section{KẾT QUẢ NGHIÊN CỨU}

3.1 Một số đặc điểm của đối tượng nghiên cứu

Bảng 3.1: những đặc điểm cơ bản của nhóm đôî tượng nghiên cứu

Số liệu được thể hiên dưới dang $\mathrm{n}(\%)$ hoặc trung vị (khoảng tứ phần vị)

\begin{tabular}{|c|c|}
\hline Tuối phát hiện bệ̂nh (năm) & $\mathbf{5 7} \pm \mathbf{1 . 2}$ \\
\hline$\leq 50$ tuổi & $7(18,9 \%)$ \\
\hline $51-60$ tuô̂i & $21(56,8 \%)$ \\
\hline$\geq 61$ tuối & $9(24,3 \%)$ \\
\hline Giới tính: $\quad \mathrm{Nam}$ & $32(86,5 \%)$ \\
\hline
\end{tabular}




\begin{tabular}{|c|c|}
\hline Nữ & $5(13,5 \%$ \\
\hline Chỉ số toàn trạng PS: 0 & $(59,5 \%)$ \\
\hline \begin{tabular}{|cc} 
& 1
\end{tabular} & $(40,5 \%)$ \\
\hline \multicolumn{2}{|l|}{ Thế mô bênh hoc } \\
\hline Ung thư biếu mô tuyến & $24(64,9 \%)$ \\
\hline Ung thư biếu mô vảy & $11(29,7 \%)$ \\
\hline Ung thư biếu mô tế bào lớn & $2(5,4 \%)$ \\
\hline \multicolumn{2}{|l|}{ Giai đoạn bệnh } \\
\hline IIIA & $10(27 \%)$ \\
\hline IIIB & $23(62,2 \%)$ \\
\hline IIIC & $4(10,8 \%)$ \\
\hline
\end{tabular}

Nhận xét: Tuổi trung bình là $57 \pm 1,2$ tuổi. Giới nam chiếm đa số $86,5 \%$. Mô bệnh học chủ yếu là carcinoma tuyến. Tỉ lệ bệnh nhân ở giai đoạn IIIB là nhiêu nhất với 62,2\%.

3.2 Sống thêm không tiến triển:

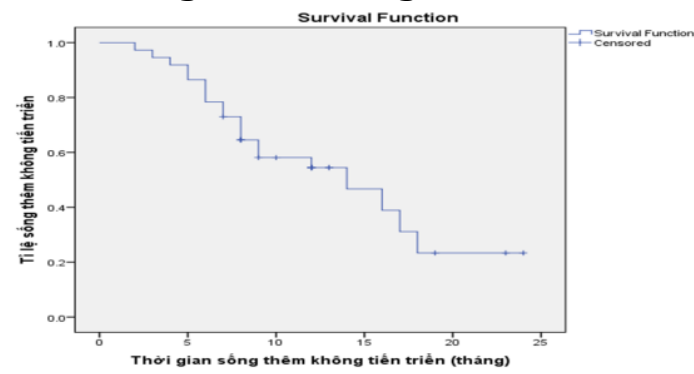

\section{Biểu đồ 3.2: Thời gian sống thêm không} tiến triên

Nhận xét: Trung vị sống không tiến triển là $14 \pm 3,7$ tháng. Sống còn không tiến triển tại thời điểm 6 tháng là 81,1\%, tại 12 tháng là 54,7\%.

\subsection{Kết quả điều trị}

Đáp ứng sau điều trị:

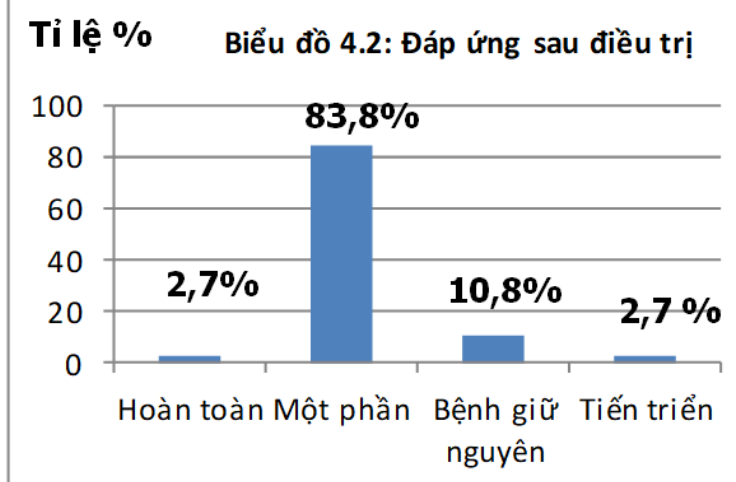

- BN đáp ứng hoàn toàn chiếm tỷ lệ $2,7 \%$, tỷ lệ đáp ứng một phần là $83,8 \%$, tỷ lệ bệnh giữ nguyên chiếm $10,8 \%$, tỉ lệ bệnh tiến triển là: 2,7\%. Tỷ lệ kiểm soát bệnh đạt được là 97,3\%.

3.4 Một số tác dụng không mong muốn của điêu trị:

Bảng 3.4: Một số tác dụng không mong muốn của điều trị:

\begin{tabular}{|c|c|c|c|c|c|c|}
\hline Độc tính & $\begin{array}{c}\text { Moí đố } \\
\text { Số BN } \\
(\%)\end{array}$ & $\begin{array}{c}\text { Đố 0 } \\
\text { Số BN } \\
(\%)\end{array}$ & $\begin{array}{c}\text { Đố 1 } \\
\text { Số BN } \\
(\%)\end{array}$ & $\begin{array}{c}\text { Đố } 2 \\
\text { Số BN } \\
(\%)\end{array}$ & $\begin{array}{c}\text { Đố } 3 \\
\text { Số BN } \\
(\%)\end{array}$ & $\begin{array}{c}\text { Đố } 4 \\
\text { Số BN } \\
(\%)\end{array}$ \\
\hline Viêm phối & $9(24,3)$ & $28(75,7)$ & $6(16,2)$ & $3(8,1)$ & 0 & 0 \\
\hline Viêm thức quản & $16(44,2)$ & $21(56,8)$ & $14(37,8)$ & $2(5,4)$ & 0 & 0 \\
\hline Viêm da & $17(45,9)$ & $16(43,2)$ & $15(40,5)$ & $2(5,4)$ & 0 & 0 \\
\hline Giảm Hb & $24(64,8)$ & $13(36,2)$ & $20(54,1)$ & $3(8,1)$ & $1(2,7)$ & 0 \\
\hline Giảm BC & $22(59,2)$ & $15(40,8)$ & $17(45,9)$ & $4(10,8)$ & $1(2,7)$ & 0 \\
\hline Giảm BCĐN & $19(48,6)$ & $28(51,4)$ & $11(29,7)$ & $7(18,9)$ & $1(2,7)$ & 0 \\
\hline Giảm TC & $5(13,5)$ & $32(86,4)$ & $4(10,8)$ & $1(2,7)$ & 0 & 0 \\
\hline Nôn & $16(43,2)$ & $24(64,9)$ & $14(35,1)$ & 0 & 0 & 0 \\
\hline Tăng men gan & $7(18,9)$ & $30(81,1)$ & $6(16,2)$ & $1(2,7)$ & 0 & 0 \\
\hline Tăng creatinin & $2(5,4)$ & $35(94,5)$ & $2(5,4)$ & 0 & 0 & 0 \\
\hline
\end{tabular}

Nhận xét: Độc tính xuất hiện trong quá trình điều trị chủ yếu là độ I, độ II, trong đó độ I chiếm đa số.

Về độc tính trên huyết học, có $59,2 \%$ bệnh nhân bị hạ số lương bạch cầu, 48,6\% bệnh nhân hạ bạch cầu trung tính, 64,8\% bệnh nhân thiếu máu và $13,5 \%$ bệnh nhân hạ tiểu cầu.

Độc tính trên hóa sinh chủ yếu là gây tăng men gan (18,9\%), độc tính gây tăng creatinin ít hơn (5,8\%). Nôn gặp ở 35.1\% bệnh nhân.

Tỷ lệ viêm thực quản do tia xạ gặp ở 44,2\% trong đó chủ yễu là viêm thực quản độ 1 chiếm tỷ lệ là 40,5\%, độ 2 chiếm 5,4\%
Tỉ lệ viêm phổi liên quan đến điều trị là $24.3 \%$, trong đó viêm phổi độ 1 chiếm $16.2 \%$, viêm phổi độ 2 là $8.1 \%$.

\section{BÀN LUÂ̂N}

Trong nghiên cứu của chúng tôi tuổi trung bình là $57 \pm 1.2$. Nhóm tuổi chiếm đa số là 51 60 tuổi, chiếm 56.8\%. TheoĐinh Công Định ${ }^{5}$, tuổi trung bình là 57 , tuổi thường gặp $50-60$ chiếm tỉ lệ cao (50\%). Chúng tôi ghi nhận nam giới chiếm 86,5\%. Lê Thị Yến ${ }^{6}$ nam giới chiếm $78,6 \%$. Qua đó chúng tôi thấy bệnh ung thư phổi thường gặp ở nam giới lớn tuổi. 
Trong nghiên cứu của chúng tôi ghi nhận bệnh nhân ở giai đoạn IIIB là nhiều nhất chiểm $62.2 \%$, tiếp đến là giai đoạn IIIA $27 \%$ và giai đoạn IIIC $10.8 \%$. Trong nghiên cứu của Lê Tuấn Anh' 74 , $2 \%$ bệnh nhân ở giai đoạn IIIA, 55.8 \% bệnh nhân ở giai đoạn IIIB. Nghiên cứu của Liang và cộng sự ${ }^{3}$ tỉ lệ bệnh nhân giai đoạn IIIA/IIIB cũng tương tự chúng tôi (26\%/74\%). Nhìn chung các nghiên cứu xu hướng chọn bệnh nhân giai đoạn IIIB, vì đây là giai đoạn rất điển hình cho sư phối hợp hóa xạ trị đồng thời.

Về phân loại mồ bệnh học, trong nghiên cứu của chúng tôi thấy ung thư biểu mô tuyến chiếm đa số $64,9 \%$. Theo nghiên cứu của Lê Thị Yến 6 , ung thư biểu mô tuyến chiếm $62,9 \%$, kết quá nghiên cứu của chúng tôi tương đồng với các tác giả khác trong nước.

Trong nghiên cứu của chúng tôi $100 \%$ bênh nhân hoàn thành 2 chu kì hóa chất EP đồng thời với xạ trị 60-63Gy. Liều xạ trên cơ quan lành được tính toán trong giới hạn cho phép.

Kết quả điều trị: Trong nghiên cứu của chúng tôi có 2,7\% bệnh nhân đáp ứng hoàn toàn, $83,8 \%$ đáp ứng một phần, $10,8 \%$ bệnh giữ nguyên, $2.7 \%$ bệnh tiến triển. Tỉ lệ đáp ứng toàn bộ là $86.5 \%$. Trong nghiên cứu của Lê Thị Yến ${ }^{6}$ tî lệ đáp ứngtoàn bộ là $78,6 \%$, tuy nhiên tất cả bệnh nhân trong nghiên cứu này ở giai đoạn IIIB. Trong nghiên cứu của Liang và $\mathrm{cs}^{3}$, tỉ lệ đáp ứng toàn bộ là $73.7 \%$, thấp hơn chúng tôi có thể do trong nghiên cứu này có tới $16.6 \%$ bệnh nhân nhận liêu xạ < 60Gy. Trong nghiên cứu của Đinh Công Định ${ }^{5}$ với kĩ thuật xạ VMAT tỉ lệ kiểm soát bệnh là $93.3 \%$ tương đồng tỉ lệ kiểm soát bệnh của nghiên cứu chúng tôi. .

Với thời gian theo dõi trung bình 13,7 tháng , chúng tôi ghi nhân trung vị sống không tiến triển là 14 tháng, sống thêm không tiến triển vào thời điểm 6 tháng là $81,1 \%$, tại 12 tháng là $54,7 \%$. Trong nghiên cứu của Hàng Quốc Tuấn ${ }^{8}$, trung vị sống thêm không tiến triển là 14 tháng. Nghiên cứu của Liang và cs $^{3}$ cũng là 14 tháng, tương đồng với NC của chúng tôi. Trong nghiên cứu của Lê Thị Yến ${ }^{6}$, thời gian sống thểm không bệnh là 15,8 tháng, cao hơn chúng tôi do trong nghiên cứu này chỉ có giai đoạn IIIB, trong khi nghiên cứu của chúng tôi có cả bệnh nhân ở giai đoạn IIIC (nhóm bệnh nhân tiên triển rất sớm trong nghiên cứu của chúng tôi).

Đánh giá tác dụng không mong muốn của điều trị, chúng tôi nhận thấy đa phần các độc tính dừng lại ở độ 1,2 và không ảnh hưởng đển quá trình điểu trị. Các độc tính liên quan đến tia xạ như viêm phổi chiếm $24,3 \%$ trong đó độ 1 chiếm $16,2 \%$ và độ 2 chiếm $8,1 \%$. Trong nghiên cứu của Lê Thị Yênn ${ }^{6}$, tỉ lệ viêm phổi do xạ chiếm $42,8 \%$, trong nghiên cứu của Hàng Quốc Tuấn ${ }^{8}$ tỉ lệ viêm phổi do xa là $20,8 \%$. Theo David $A$. Palma ${ }^{9}$, tỉ lệ viêm phổi do xạ trị là $29,8 \%$.Đối với viêm thực quản tỉ lệ trong nghiên của chúng tôi là $44,2 \%$, trong đó đô 1 chiếm $37,8 \%$, đô 2 chiếm 5,4\% cao hơn nghiên cứu của Lê Thị Yến ${ }^{6}$ là $51.4 \%$. Sự khác biệt này là do nghiên cứu của chúng tôi sử dụng kĩ thuật xạ IMRT - kĩ thuật đã được chứng minh giảm độc tính so với kĩ thuâtt xạ 3D qua nhiều nghiên cứu ${ }^{4}$. Ngoài ra các nghiên cứu cũng chỉ ra phác đồ EP trong nghiên cứu của chúng tôi cũng ít gây nguy cơ viêm phổi hơn phác đồ $\mathrm{PC}$ trong các nghiên cứu của tác giả khác. Nghiên cứu Liang và $\mathrm{Cs}^{3}$, tỉ lệ viêm phổi từ độ 2 trở lên của nhóm xa trị kểt hợp với EP (18,9\%) thấp hơn có ý nghĩ̉a thống kê so 33,3\% ở nhóm dùng $P C$ với $p=0,036$. Theo Mun Sem Liew, tỉ lệ viêm phổi do xạ của PC là $66 \%$ cao hơn EP là $33 \%$ với $p=0.033$. Kết quả của chúng tôi cũng tương đồng với Đinh Công Định ${ }^{5}$, tỉ lệ viêm phổi là $26.7 \%$, viêm thực quản là $36.7 \%$, nghiên cứu này sử dụng xạ VMAT và phác đồ giống chúng tôi. Về độc tính huyết học, có $59.2 \%$ bệnh nhân gặp tác dụng phụ hạ bach cầu, $46.8 \%$ bênh nhẩn ha bạch cầu trung tính, trong đó chỉ có $2.7 \%$ hạ độ 3, 64.8\% bệnh nhân thiếu máu, có 1 bệnh nhan thiếu máu độ 3. Độc tính trên hóa sinh gây tăng men gan $18.9 \%$, trong đó độ I là $16.2 \%$, độ II là $2.7 \%$ ), độc tính gây tăng creatinin ít hơn (5.4\%, đêu là độ I). Độc tính trên hệ tiêu hóa chủ yếu là nôn (35.5\%, độ I là $57.9 \%$, độ II là $18.4 \%)$, rất ít bệnh nhân tiểu chảy $(18.4 \%$, đều là độ I).

\section{KẾT LUÂ̂N}

Qua nghiên cứu 37 trường hợp ung thư phổi không tế bào nhỏ giai đoạn III bằng hóa xạ trị đồng thời phác đồ EP kết hợp với xạ điều biến liều không những mang lại kết quả tốt về đáp ứng và sống thêm không tiến triểnmà các độc tính liên quan đến xạ trị giảm đáng kể. Đây là hướng đi mới với nhiều triển vọng. Nhưng cần có thêm nghiên cứu trong tương lai để đánh giá về sự cải thiện của sống thêm với phác đồ này.

\section{TÀI LIÊU THAM KHẢO}

1. Cordeiro de Lima VC, Baldotto CS, Barrios $\mathbf{C H}$, et al. Stage III Non-Small-Cell Lung Cancer Treated With Concurrent Chemoradiation Followed or Not by Consolidation Chemotherapy: A Survival Analysis From a Brazilian Multicentric Cohort. JGO. 2018;(4):1-11. doi:10.1200/JGO.17.00214

2. Curran WJ, Paulus R, Langer CJ, et al. Sequential vs. concurrent chemoradiation for stage 
III non-small cell lung cancer: randomized phase III trial RTOG 9410. J Natl Cancer Inst. 2011;103(19):1452-1460. doi:10.1093/jnci/djr325

3. Liang J, Bí N, Wu $\mathbf{S}$, et al. Etoposide and cisplatin versus paclitaxel and carboplatin with concurrent thoracic radiotherapy in unresectable stage III non-small cell lung cancer: a multicenter randomized phase III trial. Annals of Oncology. 2017;28(4):777-783. doi:10.1093/annonc/mdx009

4. Boyle J, Ackerson B, Gu L, Kelsey CR. Dosimetric advantages of intensity modulated radiation therapy in locally advanced lung cancer. Adv Radiat Oncol. 2017;2(1):6-11. doi:10.1016/j.adro.2016.12.006

5. Đinh Công Định. "Đánh giá kết quả điều trị ung thư phổi không tế bào nhó giai đoạn III bằng hóa chất kết hợp xa trị VMAT tai Bênh viên K." Luân văn thạc sĩ y học, Trường đại học Y Hà Nội.:2020.
6. Lê Thi Yến. Đánh giá kết quả hóa xa tri đồng thờ phác đồ paclitaxel - carboplatin trong ung thư phổi không tê bào nhỏ giai đoan IIIB tai Bênh viên $\mathrm{K}$. Luận án tiến sĩ y học, Trường đại học Y Hă Nội. 2019.

7. Lê Tuấn Anh. "Hóa-xa trị đồng thời ung thư phổi không tế bào nhỏ giai đoạn III." Luận án tiến sĩ y học, Trường đại học Y Dược TP Hồ Chí Minh. Published online 2015.

8. Hàng Quốc Tuấn và cs. Đánh giá kết quả điều trị ung thư phổi không tế bào nhỏ giai đoạn III không mố được bằng phác đồ hóa chất PaclitaxelCarboplatin kết hợp hóa xa đồng thời . Tap chí ung thư hoc Viêt Nam, 4, 68-75. Published online 2020.

9. Palma DA, Senan $S$, Tsujino $K$, et al. Predicting radiation pneumonitis after chemoradiation therapy for lung cancer: an international individual patient data meta-analysis. Int J Radiat Oncol Biol Phys. 2013; 85(2):444-450. doi:10.1016/ j.ijrobp.2012.04.043

\title{
KIẾN THỨC VÀ HÀNH VI TÌNH DUUC AN TOÀN CỦA NGƯỜI DI CƯ LAO ĐộNG TỰ DO TAI PHƯỜNG HOÀNG LIẸTT, QUÂ̂N HOÀNG MAI, THẦNH PHỐ HÀ NộI NĂM 2021
}

\author{
Trần Thị Thanh Thủy ${ }^{1}$, Nguyễn Ngọc Kiều $\mathrm{Anh}^{2}$
}

\section{TÓM TẮT}

Kết quả: Điều tra mô tả cắt ngang trên 209 đối tượng là người di cư lao động tự do tại phường Hoàng Liệt, quận Hoàng Mai, Hà Nội năm 2021 nhằm mô tả kiến thức và hành vi tình dục an toàn và môt số yếu tố liên quan. Chọn mẫu theo phương pháp thuận tiện và Snowball Sampling, sử dung bố công cư tư điền khuyết danh để thu thập số liệu. Kết quả nghiển cứu cho thấy người di cư lao động tự do có kiến thức tình dục an toàn đạt khá cao chiếm $70,33 \%$. Tuy nhiên kiến thức về thời điểm dế có thai nhất trong chu kỳ kinh nguyệt khá thấp (35\% nam và $58 \%$ nữ). Các đối tương tham gia nghiên cứu đã nghe nói về tình dục an toàn, nhưng để hiểu về tình dục an toàn còn chưa được cao.

Tư khoá: Tình dục an toàn, di cư, lao động tự do, Hà Nô̂i.

\section{SUMMARY \\ KNOWLEDGE AND BEHAVIOURS OF SAFE SEX OF FREELANCE WORKERS IN HOANG LIET WARD, HOANG MAI DISTRICT, HANOI CITY IN 2021}

A cross-sectional study was conducted on 209 subjects freelance migrant workers in Hoang Liet ward, Hoang Mai district, Hanoi in 2021 for the purpose of describing knowledge and total sexual

*Trường Đại học Y Hà Nội

Chịu trách nhiệm chính: Trân Thị Thanh Thủy

Email: Tranthanhthuy@hmu.edu.vn

Ngày nhận bài: 29.7.2021

Ngày phản biên khoa họ: 29.9.2021

Ngày duyệt bài: 4.10.2021 behavior and a number of important factor links. Select the sample by the method and Snowball Sampling, use the anonymous tooler to collect the data. Research results for self-employed workers show that having full educational knowledge is quite high, accounting for $70.33 \%$. However, knowledge about the most fertile time in the menstrual cycle is quite low (35\% of men and $58 \%$ of women). Study of the whole population, the subjects had heard about the education landscape, but their understanding of the education landscape was not very high.

Keywords: safe sex, migration, freelance workers, Hanoi

\section{I. ĐĂT VẤN ĐỀ}

Theo thống kê đến giữa năm 2019, số người di cư toàn cầu là 271,6 triệu người, tăng 0,7 điểm so với năm 20001, điều này chứng tỏ nhu cầu tìm việc làm, nơi ở mới, môi trường giáo dục mới không ngừng tăng cao, thu hút đông đảo nguồn lực cũng như chất xám đổ về những khu vực, quốc gia phát triển kinh tế, văn hoá, xã hội mạnh. Trong làn sóng lao động di cư thì đối tượng lao động tự do đang chiếm đông đảo và ngày một tăng mạnh, đặc biệt trong các ngành dịch vụ. Đây cũng là đối tượng mà gân đây được xã hội quan tâm hơn cả bởi toàn bộ lao động này đều không có hợp đồng lao động, cũng có nghĩa là họ không có hoặc phải tự xoay xở để có được môt loat quyền lợi cơ bản của người đi làm: Bảo hiểm xã hội dành cho hưu bổng, bảo hiểm thất nghiệp khi không có việc làm. Những khó khăn về kinh tế, xã hội thì những người di 